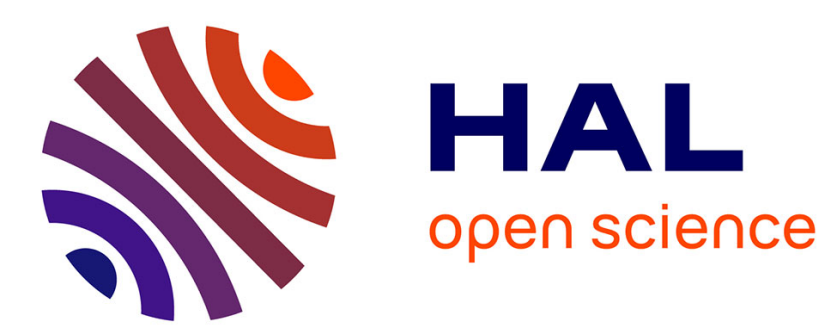

\title{
Oxygen plasma modification of pitch-based isotropic carbon fibres
}

Jean-Paul Boudou, J.I. Paredes, A. Cuesta, A. Martinez-Alonso, J.M.D.

Tascon

\section{- To cite this version:}

Jean-Paul Boudou, J.I. Paredes, A. Cuesta, A. Martinez-Alonso, J.M.D. Tascon. Oxygen plasma modification of pitch-based isotropic carbon fibres. Carbon, 2003, 41, pp.41-56. 10.1016/S00086223(02)00270-1 . bioemco-00156931

\section{HAL Id: bioemco-00156931 https://hal-bioemco.ccsd.cnrs.fr/bioemco-00156931}

Submitted on 24 Jun 2007

HAL is a multi-disciplinary open access archive for the deposit and dissemination of scientific research documents, whether they are published or not. The documents may come from teaching and research institutions in France or abroad, or from public or private research centers.
L'archive ouverte pluridisciplinaire HAL, est destinée au dépôt et à la diffusion de documents scientifiques de niveau recherche, publiés ou non, émanant des établissements d'enseignement et de recherche français ou étrangers, des laboratoires publics ou privés. 


\title{
Oxygen plasma modification of pitch-based isotropic carbon fibres
}

\author{
J.P. Boudou ${ }^{\mathrm{a}}$, J.I. Paredes ${ }^{\mathrm{b}}$, A. Cuesta ${ }^{\mathrm{b}}$, A. Martinez-Alonso ${ }^{\mathrm{b}}$, J.M.D. Tascon ${ }^{\mathrm{b}}{ }^{*}$ \\ ${ }^{\mathrm{a}}$ Université Pierre et Marie Curie, CNRS, Case 124, 4 Place Jussieu, Paris Cedex 05 75252, France \\ b Instituto Nacional del Carbon,' CSIC, Apartado 73, 33080 Oviedo, Spain
}

\begin{abstract}
An isotropic carbon fibre was surface-treated by microwave oxygen plasma at different conditions and characterised by scanning electron microscopy (SEM), scanning tunneling microscopy (STM), $\mathrm{N}_{2} / \mathrm{CO}_{2}$ adsorption, Raman spectrometry, $\mathrm{X}$-ray photoelectron spectroscopy (XPS) and temperature-programmed desorption (TPD). It is shown that the structure of the fibre suffers only limited alterations upon plasma treatment in such a way that the local disorder on its surface, which was already large in the fresh material, barely increases after the plasma exposure, as detected by Raman measurements. At the nanometre scale, STM images revealed a moderate increase in surface roughness. Evidence for chemical changes undergone by the fibre following the etching was provided by XPS and TPD, showing that stable oxygen functionalities were introduced by the plasma exposure, a result of practical importance for the application of this treatment not only to this type of carbon fibre, but to carbon materials in general. It was also observed that very gentle plasma exposures were generally sufficient to provide the fibre surface with a large amount of oxygen functional groups and that more intense treatments had a negative effect in this respect (i.e. they were not able to supply oxygen to the surface in larger amounts than the softer treatments did).
\end{abstract}

Keywords: A. Carbon fibres; B. Plasma reactions; C. Temperature programmed desorption; X-ray photoelectron spectroscopy; D. Surface properties

\section{Introduction}

From a technological point of view, the surface modification of carbon materials is of great importance in a wide variety of fields, such as biomedicine [1,2], electrochemistry [3,4], microelectronics [5] and thin-film technology [6]. The surface modification is accomplished through different types of treatments: thermal, wet chemical or electrochemical oxidation, plasma treatment, ion or cluster bombardment, covalent linkage of biomolecules, etc. The ultimate goal of these treatments is to change the surface chemistry and microstructure of the material and thus modulate a number of properties: biocompatibility, roughness, reactivity, conductivity, etc.

In this context, surface modification of carbon fibres by

*Corresponding author. Tel.: 134-98-511-9090; fax: 134-98529-7662.

E-mail address: tascon@incar.csic.es (J.M.D. Tascon).' oxidation is a topic of great interest [7-16]. Particularly, low-temperature oxygen plasma provides a means of conveniently introducing surface oxygen functional groups rapidly and cleanly on carbon surfaces with minimal burnoff and structural damage of both the bulk and the near surface. Oxygen functional groups, many of which are of acidic and hydrophilic character [17-19], improve the surface properties by increasing the wettability [12], the chemisorption activity, the adhesion potential [13], etc., and are deemed to be highly relevant for the application of, e.g., carbon fibres as reinforcement of composite materials $[16,20-23]$. They can, for instance, control the chemical bonding with a phenolic resin where the hydroxyl group can react with carboxylic groups present on the fibre surface and form a strong covalent, ester type bonding. Steady-state concentration of the oxygen groups is approached [22], presumably due to two competing effects; that is, the removal of surface atoms or clusters of atoms by etching reactions, and addition reactions between 
reactive sites and the reactant oxygen species in the plasma. In all cases, the plasma would only modify the outermost layers of the fibre: the low activation energy needed by atomic oxygen species to react with carbon atoms would not allow them to diffuse towards the internal surface.

Carbon surface oxidation by oxygen plasma would be somewhat easier on disordered carbon structures than on highly ordered ones such as graphite [24-28]. The treatment time needed to achieve the desired changes in fibre surface chemistry is of the order of several seconds to a few minutes. Subsequently, upon exposure of the plasma-treated material to the ambient, post-reaction aging effects lead to a restructuring of the surface towards a new stable thermodynamic equilibrium in which the chemistry may differ somewhat from that originally created by the plasma [29-34]. Carbon dangling bonds left behind by the plasma which had not chemisorbed oxygen when the treatment was over would be a source of further oxygen incorporation during storage.

This work forms part of a general study of the surface modification of carbon materials by means of oxygen plasma $[16,27,28,35-41]$, and has as one of its objectives the assessment of the effects of this type of treatment on isotropic carbon fibres. To this end, plasma-treated samples were analysed using a variety of surface techniques.

\section{Experimental}

\subsection{Materials}

The starting material employed in this study was a virgin (i.e. without surface treatment and without sizing) isotropic petroleum pitch-based carbon fibre (Donacarbo S233) manufactured by Osaka Gas. This type of carbon discontinuous fibre has low mechanical properties (nominal modulus and tensile strength of 38 and $0.7 \mathrm{GPa}$, respectively), and presents a disordered carbon skeleton. Elemental analysis (carried out in a LECO CHNS-932 microanalysis apparatus with a LECO VTF-900 accessory for oxygen) yielded (wt.\%, dry basis): $94.02 \% \mathrm{C}, 0.89 \% \mathrm{H}$, $1.06 \% \mathrm{~N}, 0.37 \% \mathrm{~S}$ and $3.74 \% \mathrm{O}$.

\subsection{Plasma treatment}

Plasma treatments were carried out in a plasma processor, Technics Plasma 200-G, where an oxygen plasma was generated using $2.45 \mathrm{GHz}$ microwave radiation. The microwave field was generated by means of a magnetron, and a waveguide was employed to transfer microwave power between this source and the point of use, which was a quartz reactor (batch type) where the plasma was created and the carbon fibre samples were placed. A dielectric window connected the waveguide with the quartz reactor. During the etching, a flow rate of pure oxygen was introduced so as to produce 1.0 mbar ( 0.75 Torr) pressure inside the reaction chamber. As discussed elsewhere [27], this plasma configuration leads to an etching dominated by the chemical reactions between the reactive species from the plasma (oxygen atoms) and the carbon atoms from the sample, the ion bombardment playing a secondary role in the process. To achieve results being as reproducible as possible, all the samples were placed in the chamber in the same fashion. The samples were prepared by spreading the specimen over Petri dishes with an exposure density of

$10^{22} \mathrm{~g} \mathrm{~cm}_{22}$.

The severity of the plasma treatment was varied by modulating the microwave power and duration of the treatment as follows: $20 \mathrm{~W} / 1 \mathrm{~min}, 50 \mathrm{~W} / 1 \mathrm{~min}, 75 \mathrm{~W} / 3$ $\mathrm{min}$, and $150 \mathrm{~W} / 5 \mathrm{~min}$ (increasing order of severity)

\section{2 .3. Scanning electron microscopy (SEM)}

SEM studies were carried out with a Zeiss DSM microscope. Individual fibres were examined and typical values of voltage and working distance of operation were $10 \mathrm{kV}$ and $5 \mathrm{~mm}$, respectively.

\subsection{Scanning tunneling microscopy (STM)}

For the STM measurements, bundles of fresh and plasmatreated fibres were attached to sample holders by means of carbon adhesive tape. In order to avoid unwanted interactions between the fibres and parts of the STM tips other than their very apex, those fibres that were protruding from the sample were carefully removed. STM imaging was performed in air at room temperature with a Nanoscope Multimode IIIa from Digital Instruments using mechanically prepared Pt/Ir (80/20) tips. Several different tips were used to check for the reproducibility of the results. The images were acquired in the constant current mode at typical tunneling currents of $0.5 \mathrm{nA}$ and bias voltages of $500 \mathrm{mV}$. To improve the visual presentation of the images, a low-pass filter was applied once. Special care was taken to ensure that no features were lost or artefacts introduced in the images by this procedure. To further evidence the effect of the different plasma treatments on the fibres, quantitative information was extracted from the STM images. The power spectral density (PSD) plots for the images of the untreated and plasma-treated fibres were calculated as a mean angular value of the fast Hartley transform (FHT) [42], and describe the surface roughness for the different spatial wavelengths (or frequencies).

\subsection{Textural characterization by gas adsorption}

Adsorption isotherms of $\mathrm{N}_{2}(77 \mathrm{~K})$ and $\mathrm{CO}_{2}(273 \mathrm{~K})$ were obtained in a semiautomatic adsorption apparatus (Nova-1200, Quantachrome). Before the measurements, the samples were degassed at $523 \mathrm{~K}$ under vacuum for 12 $\mathrm{h}$ in the degas port of the adsorption apparatus prior to the 
adsorption experiment. The densities and cross-sectional areas of the adsorbates employed were taken to be, respectively, $0.8129 \mathrm{~g} \mathrm{~cm}^{23}$ and $0.162 \mathrm{~nm}^{2}\left(\mathrm{~N}_{2}, 77\right.$ $\mathrm{K})$, and $1.182 \mathrm{~g} \mathrm{~cm}^{23}$ and $0.1705 \mathrm{~nm}^{2}\left(\mathrm{CO}_{2}, 273 \mathrm{~K}\right)$. The surface area for the samples under study was calculated following the standard BET method [43]. The total pore volume $\left(\mathrm{N}_{2}\right)$ was calculated by converting the amount of $\mathrm{N}_{2}$ adsorbed at a relative pressure of 0.90 into volume of liquid adsorbate. The equivalent micropore surface area and the volume of narrow micropores were obtained from the isotherm of $\mathrm{CO}_{2}$ at 273 $\mathrm{K}$ by application of the Dubinin-Radushkevich (DR) equation.

\subsection{Raman microprobe spectrometry}

Raman analysis was performed with an XY multichannel Raman microspectrometer (DILOR) using the green $(514.5 \mathrm{~nm})$ exciting radiation from an argon ion laser. The surface material output powers and integration times were $20 \mathrm{~mW}$ and $500 \mathrm{~s}$, or $100 \mathrm{~mW}$ and $60 \mathrm{~s}$, respectively, which makes the energy irradiated onto the sample low enough (ca. 5 and $25 \mathrm{~mW}$, respectively) to avoid any apparent damage (checked under the optical microscope) to the sample surface. The laser spot size was , $1 \mathrm{~mm}$. Spectra were measured in the $900-1900 \mathrm{~cm}^{21}$ (1st-order spectrum) and 2500-3300 $\mathrm{cm}^{21}$ (2nd-order spectrum) ranges.

\section{2 .7. X-ray photoelectron spectroscopy (XPS)}

XPS data were acquired from virgin and plasma-treated fibres. The measurements were performed at ITODYS in the University of Paris 7. A Surface Science Instrument (SSI) spectrometer equipped with a monochromatic $\mathrm{Al} \mathrm{Ka}$ $\mathrm{X}$-ray source $(1486.6 \mathrm{eV})$ was used at a spot size of 600 $\mathrm{mm}$. Carbon fibres were placed in an especially designed support ensuring that no signal was observed from the sample holder. The pass energy was set at 150 and $50 \mathrm{eV}$ for the survey and the high resolution spectra, respectively. The instrument was operated with an analyzer chamber pressure of $10^{29}$ mbar or less, and with the axis of the energy analyser at $90^{8}$ relative to the nominal plane of the sample surface and operated in fixed transmission mode. The XPS sampling depth for a take-off angle of $90^{8}$ is estimated to be about $6 \mathrm{~nm} \mathrm{[29]} \mathrm{(for} \mathrm{flat}$ samples); however, one must take into account that surface roughness, defects, and the curvature of fibres can affect the depth $[44,45]$. The step size was $1.12 \mathrm{eV}$ for the survey spectrum and 0.078 or $0.096 \mathrm{eV}$ for the highresolution spectra. Charge compensation was achieved with a flood gun of $0-1 \mathrm{eV}$ electrons using standard procedures for this spectrometer. All spectra were energy calibrated by assigning $284.5 \mathrm{eV}$ to the $\mathrm{C} 1 \mathrm{~s}$ binding energy of the 'graphitic' peak. Data processing was achieved with Winspec software, kindly supplied by the Laboratoire Interdisciplinaire de Spectroscopie d'Electrons (LISE), Namur, Belgium.
Surface atomic compositions were calculated from the areas of the peaks from survey spectra after fitting of a Shirley background, which was subtracted prior to quantification and correcting the relative peak areas using the (Wagner) manufacturer's sensitivity factors [46]. High resolution envelopes were fitted using mixed LorentzianGaussian curves. The Lorentzian-Gaussian mixture was taken as 0.5 , except for the main (graphitic) peak, which was taken at 0.84 with an exponential tail. Peak width ranged from 0.9 to $1.15 \mathrm{eV}$.

\section{2 .8. Temperature-programmed desorption (TPD)}

The TPD technique [47] analyses the evolution of $\mathrm{H}_{2} \mathrm{O}$, $\mathrm{CO}_{2}$, $\mathrm{CO}$ and $\mathrm{H}_{2}$ evolving from the thermal decomposition of oxygen complexes under an inert atmosphere. Samples (5-10 mg) were treated in flowing helium, $99.9995 \%$ pure $\left(5 \mathrm{ml} \mathrm{min}^{21}\right.$, atmospheric pressure), at $20 \mathrm{~K} \min ^{21}$ from 300 to $1700 \mathrm{~K}$. Evolved gases were detected with a Leybold Quadrex 100 mass spectrometer using a differential pumping. External calibration was done by means of reference gas mixtures and signal shift was corrected by internal calibration with neon ( $1 \mathrm{vol} . \%$ in the carrier gas) [48]. The sample holder was an open spoon-shaped crucible with a U section $5 \mathrm{~mm}$ long. It was introduced into an alumina tube (6 mm O.D. and $4 \mathrm{~mm} \mathrm{I.D.).} \mathrm{This}$ alumina tube was itself placed at the centre of a horizontal electric furnace (60 mm long and $7 \mathrm{~mm} \mathrm{I.D.)}$

\section{Results and discussion}

\subsection{SEM}

The as-received carbon fibres are approximately circular in cross-section, having a smooth surface with no noticeable micro-morphological features. Within the resolution of the SEM technique, the fibre appeared isotropic (no preferred orientation). Some untreated fibres presented thin flakes deposited on the surface. These flakes may be the result of some contamination during the fibre manufacturing.

Plasma oxidation does not appear to greatly affect the external fibre surface on the micron scale. The characterization of fresh and plasma-treated samples by SEM showed that, even for the most intense treatments, the external surface remains smooth and the fibres keep their initial diameter, and only the flakes tend to disappear after plasma treatment. Thus, the plasma oxidation has a 'cleaning' effect. At the magnification levels attained by SEM, the structure of the treated surfaces appeared identical to that of the untreated fibres. Fig. 1 shows the SEM micrograph of a fibre exposed to $50 \mathrm{~W} / 1$ min oxygen plasma. No etching or pitting can be observed, and the same behaviour applies to that of the other treatments. As the external appearance of the fibres did not appear to be 


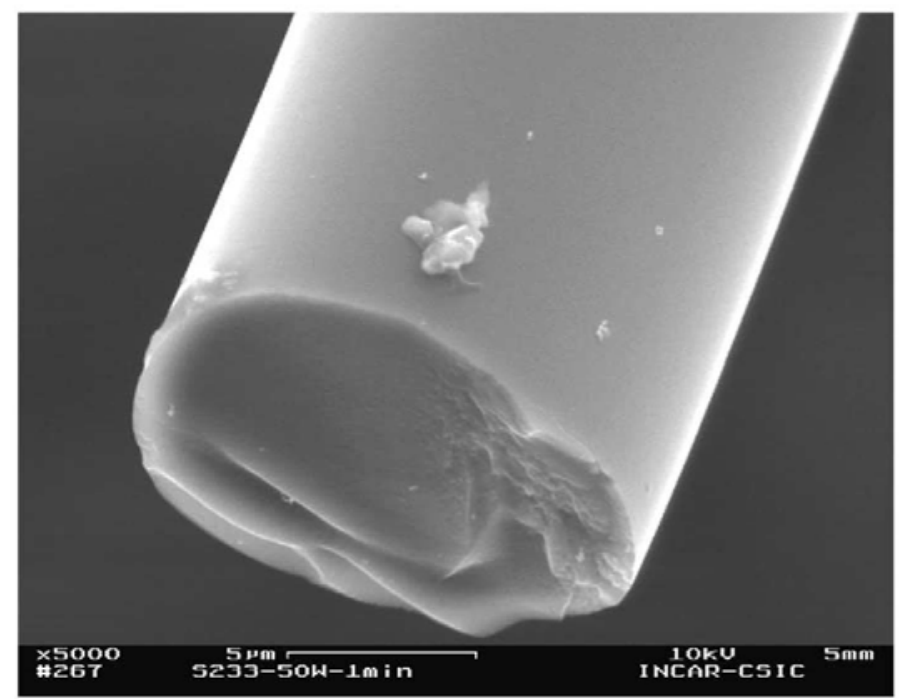

Fig. 1. SEM micrograph showing the fracture cross-section of carbon fibre treated by oxygen plasma at $50 \mathrm{~W}$ for $1 \mathrm{~min}$.

altered at the SEM microscale, one could assume that their tensile strength properties will not be severely degraded by using plasma oxidation to modify their surface.

\subsection{STM}

The STM images showed evidence of much subtler changes in the nanomorphology of the carbon fibre surface upon plasma treatments. The fresh fibres (Fig. 2) present a relatively smooth topography comprised of approximately rounded or slightly elongated platelets with lateral dimensions of about 10-20 nm. By contrast, upon oxygen plasma treatments all the samples displayed a considerably rougher morphology, as can be noticed in Figs. 3 (50 W/ 1 $\mathrm{min}), 4(75 \mathrm{~W} / 3 \mathrm{~min})$, and 5 (150 W/5 min), suggesting an increase in their surface areas compared to that of the fresh fibre. The ratios between the STM surface area (calculated as the topographical area of a large number of images) of the different plasma-treated samples and that of the fresh fibre are 1.145 for the $50 \mathrm{~W} / 1$ min sample, 1.112 for the $75 \mathrm{~W} / 3 \mathrm{~min}$ sample, and 1.425 for the $150 \mathrm{~W} / 5$ min sample. This increment in normalized STM surface area ratios (related to surface roughness) of the plasmamodified fibres as compared to the fresh material should be beneficial for their application as reinforcement in composite materials, since a rougher fibre topography would lead to a higher degree of mechanical interlocking between fibre and matrix surfaces [27]. As might be expected, the highest STM surface area corresponds to the fibre treated under the most severe condition (150 $\mathrm{W} / 5 \mathrm{~min})$. However, no significant difference in STM surface area is found between the other two

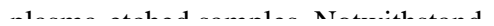

ing these facts, their surface features are noticeably different as concerns their lateral dimensions. In the case of the $75 \mathrm{~W} / 3 \mathrm{~min}$ sample, the surface features have lateral sizes ranging from about 10 up to $30 \mathrm{~nm}$, whereas those of the $50 \mathrm{~W} / 1$ min one are always below $20 \mathrm{~nm}$ and can be as small as $5 \mathrm{~nm}$. Therefore, the former presents bigger features than the latter. In this respect, the $75 \mathrm{~W} / 3 \mathrm{~min}$ sample is more similar to the $150 \mathrm{~W} / 5 \mathrm{~min}$ one, whose features are also typically between 10 and $30 \mathrm{~nm}$. The difference between the two essentially lies, as noted previously, in the vertical heights of the features (i.e. the roughness), which results in different STM surface areas.

To further evidence the effect of the different plasma treatments on the fibres, power spectral density (PSD) plots are presented in Fig. 6 . These plots were calculated as a mean angular value of the fast Harley transform of the images [42]. They describe the surface roughness for the different spatial wavelengths (or frequencies) in the images and have proved to be useful in quantitatively evidencing differences between plasma-modified surfaces $[27,49]$. It can be noticed in the plots that, in general, more intense treatments lead to surfaces with higher values of the PSD, especially at intermediate and high frequencies, i.e. those roughly corresponding to the features typically observed in the images, and so confirm the general increase in roughness with the plasma treatments. As was the case with the normalized STM surface area ratios, there is a similarity between the PSD plots of the $50 \mathrm{~W} / 1$ min and 75 W/3 min samples. However, the PSD values of the former are slightly higher in the 80 to $240 \mathrm{~mm}^{21}$ region, which corresponds to features between about 4 and $12 \mathrm{~nm}$. This is consistent with the previously mentioned finding of features of that size range in the 50 

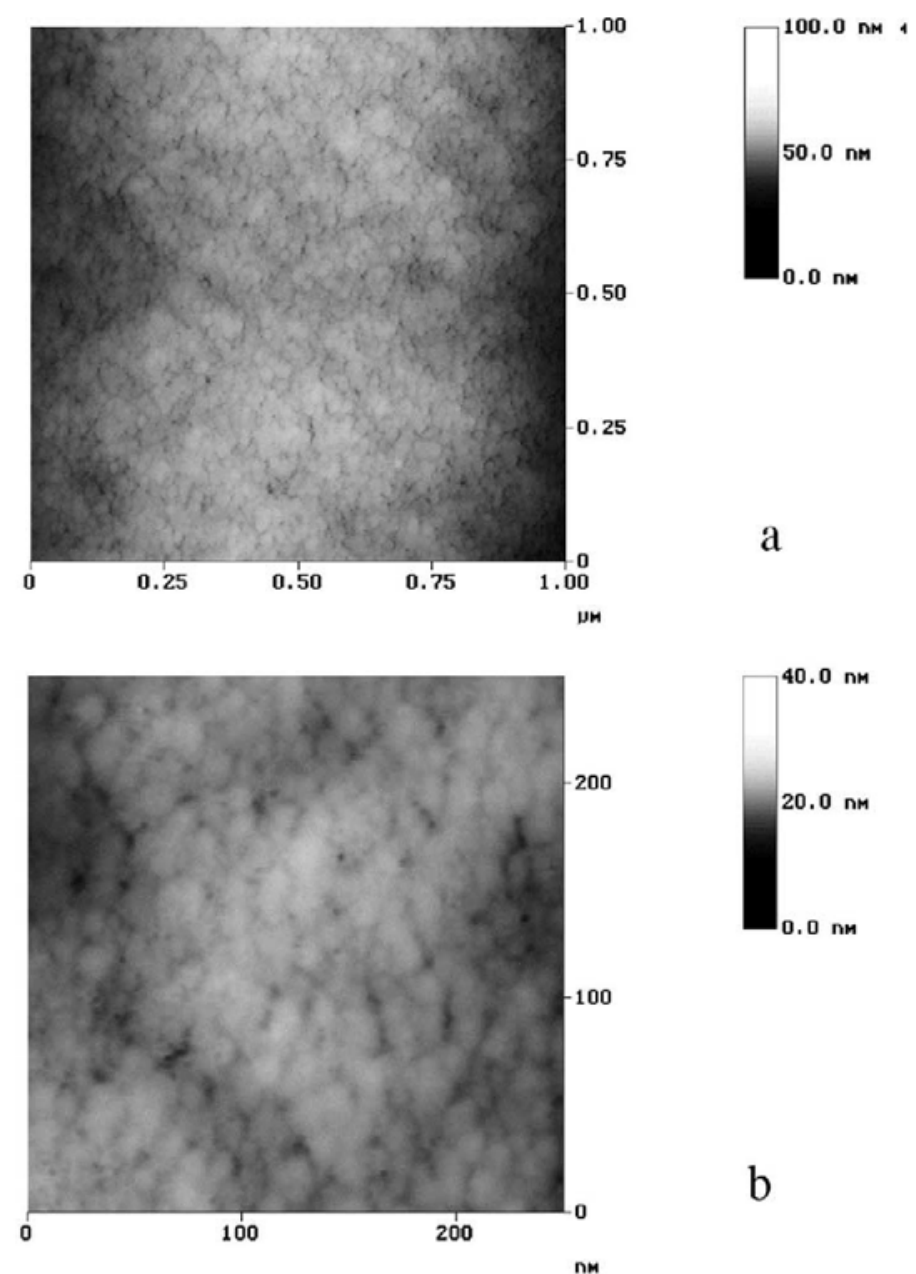

$\mathrm{b}$

Fig. 2. STM images (low (a) and high (b) magnification) of untreated carbon fibre.

fact that they were not so evident in the $75 \mathrm{~W} / 3 \mathrm{~min}$ sample.

\subsection{Gas adsorption}

Results for surface areas and pore volumes calculated from $\mathrm{N}_{2}$ and $\mathrm{CO}_{2}$ adsorption are presented in Table 1. Data include the micropore volume calculated by fitting the Dubinin-Radushkevich equation to $\mathrm{CO}_{2}$ adsorption results $\left(V_{\mathrm{DR}}\right)$, the total pore volume calculated from $\mathrm{N}_{2}$ adsorption at a relative pressure of 0.90 (Vp/p050.90), the micropore equivalent surface area calculated from $V_{\mathrm{DR}}\left(S_{\mathrm{mp}}\right)$ and the BET surface area (SBET) calculated from $\mathrm{N}_{2}$ adsorption results.

As can be deduced from the $V p / p 050.90$ values listed in Table $1, \mathrm{~N}_{2}$ adsorption at $77 \mathrm{~K}$ on the carbon fibres under study is almost nil (all the $\mathrm{N}_{2}$ isotherms at $77 \mathrm{~K}$ belonged to type II in the BDDT classification) [43]. However, $\mathrm{CO}_{2}$ adsorption at $273 \mathrm{~K}$ is relatively large, a fact that is ascribable to the occurrence of very narrow micropores (pore width ,0.7 nm) where $\mathrm{N}_{2}$ adsorption at $77 \mathrm{~K}$ is kinetically restricted by activated diffusion. This behaviour towards the $\mathrm{N}_{2} / \mathrm{CO}_{2}$ couple is typical of carbonised residues from coals, lignocellulosic materials or organic polymers, as well as activated carbon materials with very low burn-off degrees [30,50]. Plasma treatment at a microwave power of $50 \mathrm{~W}$ for $1 \mathrm{~min}$ brought about an increase in the micropore volume measured by $\mathrm{CO}_{2}$ adsorption and then a decrease of it under more severe conditions (Table 1 ), presumably as a result of pore widening due to oxygen gasification of the entrance of micropores situated mainly near the external surface of the sample; this would agree with the increase in surface roughness detected by STM. The BET surface area $\left(S_{\mathrm{BET}}\right)$ of the fresh fibres was very small (close to the estimated 

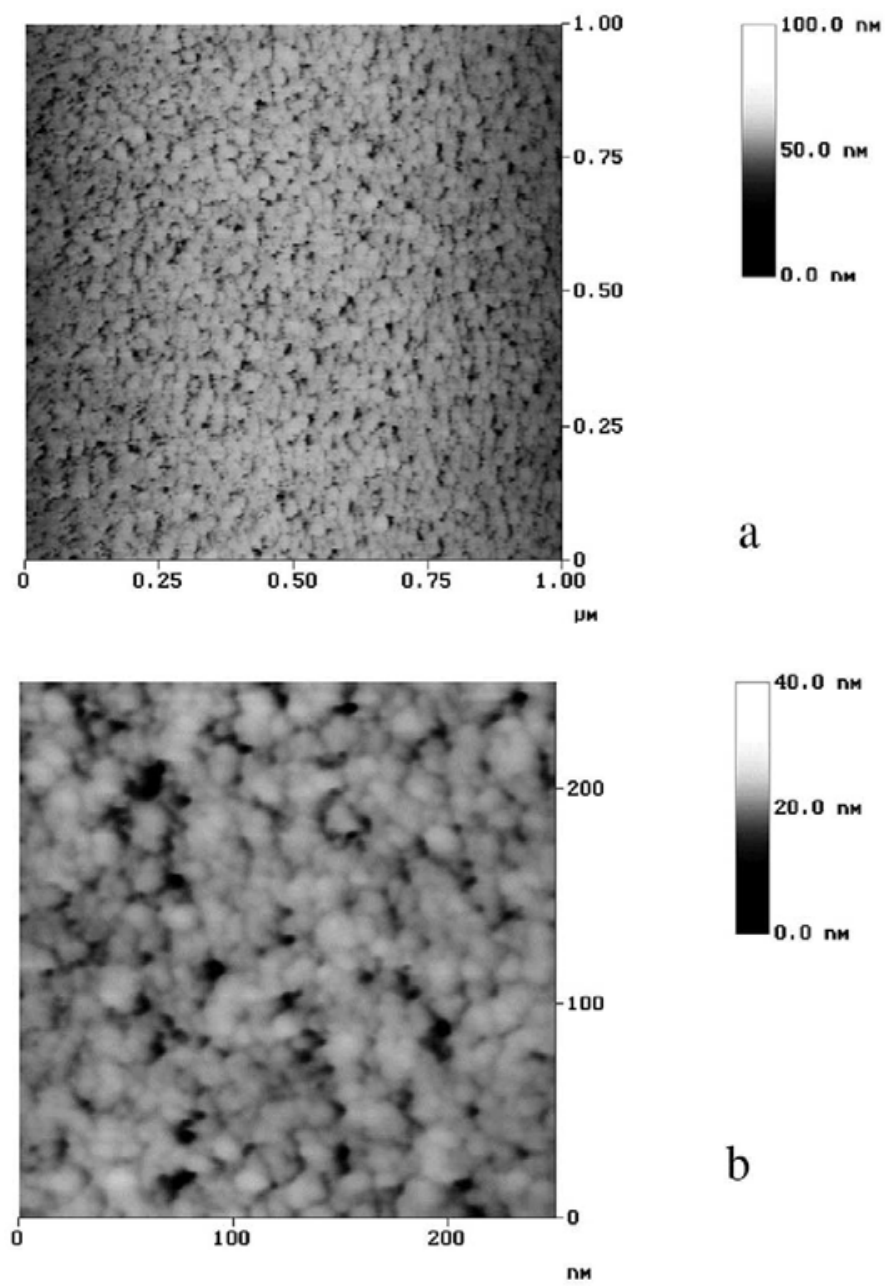

a

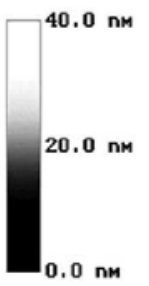

b

Fig. 3. STM images (low (a) and high (b) magnification) of carbon fibre treated by oxygen plasma at $50 \mathrm{~W}$ for 1 min.

geometric surface area of about $0.18 \mathrm{~m}^{2} \mathrm{~g}^{21}$ ) and increased with increasing severity of the oxygen plasma treatment. This increase was especially important for the most severe plasma treatment conditions and coincided with a decrease in the nar ${ }^{\mathrm{r}}$ owest microporosity as deduced from $\mathrm{CO}_{2}$ adsorption results, which suggests that the plasma treatment causes some opening of micropore constrictions. In studying the effects of oxygen plasma treatment on glass-like carbon spheres, Inagaki et al. [51] observed no change in the isotherms of $\mathrm{CO}_{2}$, but a marked decrease of $\mathrm{N}_{2}$ adsorption was detected which was attributed to changes in both porous texture and nature of surface centres. Domingo-Garcia' et al. [52] reported that a mesoporous glassy carbon modified by $\mathrm{O}_{2}$ plasma treatment underwent practically no changes in $\mathrm{N}_{2}$ and $\mathrm{CO}_{2}$ adsorption; the micropore volume increased slightly at small burn-off degrees. On the other hand, the same authors reported a dramatic drop in the surface area measured by $\mathrm{N}_{2}$ adsorption upon plasma treatment of a microporous glassy carbon [52], and this was explained as a consequence of the fixation of oxygen chemical functionalities at the entrance of the micropores which are mainly near the external surface of the sample. Jang and Yang [53] observed a significant increase in the BET surface area (from , $1 \mathrm{~m}^{2} \mathrm{~g}_{21}$ to $\mid 4 \quad \mathrm{~m}^{2} \mathrm{~g}^{21}$ ) upon oxygen plasma treatment of a carbon fibre (T300 from Toray); this was attributed to micro-pits on the CF surface area developed upon the oxygen plasma treatment. In our case, the increase in the degree of surface roughness (STM surface area) of the plasma-treated samples, which shows the maximum value for the strongest treatment, can in part justify the observed increase in $S_{\text {BET. }}$

\subsection{Raman microprobe spectrometry}

Raman microprobe spectrometry can be used as a tool for the surface characterization of partially ordered carbon materials, with an estimated analysis depth of $100 \mathrm{~nm}$ [54]. 

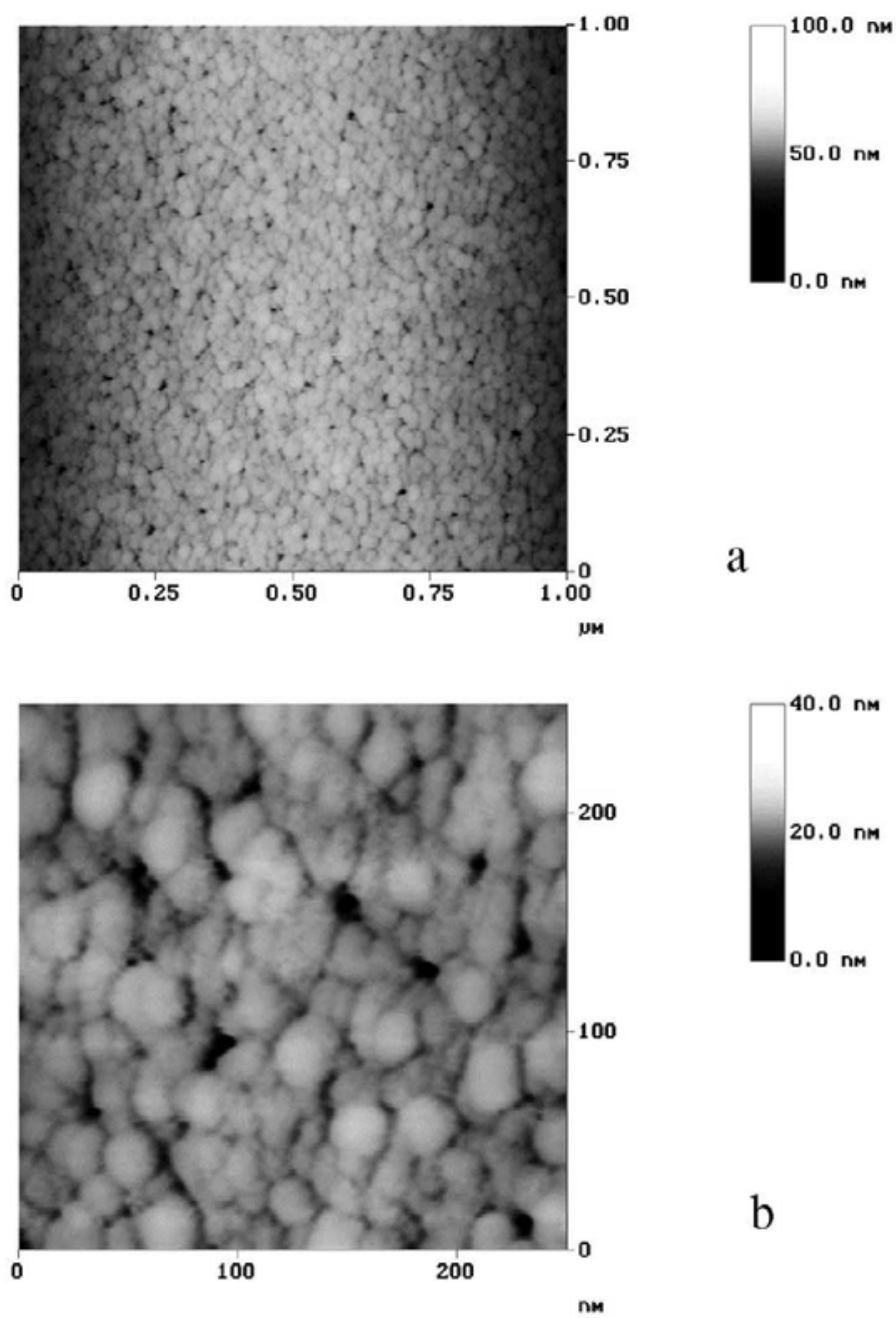

b

Fig. 4. STM images (low (a) and high (b) magnification) of carbon fibre treated by oxygen plasma at $75 \mathrm{~W}$ for 3 min.

Plasma oxidation is expected to introduce some degree of surface disorder measurable by Raman spectrometry. The 1st-order spectrum presents for all studied samples two relatively broad bands centred at | $1580 \mathrm{~cm}^{21}$ and | 1380 $\mathrm{cm}^{21}$ and a heavy overlapping between them (a situation typical of poorly organized materials). Band positions were analysed using a mixed Gaussian-Lorentzian curve-fitting procedure. As found previously for a variety of disordered carbon materials [54-58], the best curve fitting was obtained using mixtures of Gaussian and Lorentzian line shapes with three bands at $1587-1600 \mathrm{~cm}^{21}$ ( $\mathrm{G}$ band, typical of graphitic order), 1345-1350 $\mathrm{cm}^{21}$ (D band, typical of structural disorder and defects), and 1503$1534 \mathrm{~cm}^{21}$ ( $\mathrm{D}^{0}$ band, associated with amorphous $\mathrm{sp}_{2}-$ bonded forms of carbon or interstitial defects [55]). The 2nd-order Raman envelope was very weak, typical for disordered carbons.

The positions, widths and relative intensities of the different bands constituting the 1st-order spectra are given in Table 2 (all of these parameters have been shown to be suitable indicators for the degree of structural order in carbon materials [56]). The large values found for the D-band width $\left(W_{\mathrm{D}}\right)$ indicate a highly disordered carbon microstructure, suggesting that the studied fibres had been submitted to treatment at a low temperature during their production. It can also be noticed that various peak parameters change somewhat upon plasma etching. As Table 2 shows, plasma treatments in general brought about a slight rise in the ${ }_{I D / I G}$ and $W_{\mathrm{D}} / W_{\mathrm{G}}$ ratios, indicative of an increase in the degree of disorder [59], which would occur through the breaking of aromatic bonds and/or the reduction of surface crystallinity [60]. This is more evident in the spectra obtained using a $20 \mathrm{~mW}$ laser, which may be considered as more reliable than those obtained at 100 $\mathrm{mW}$ : a higher power level could produce some laser-induced sample heating [61,62], even though no $\therefore \ldots$... $c$ 

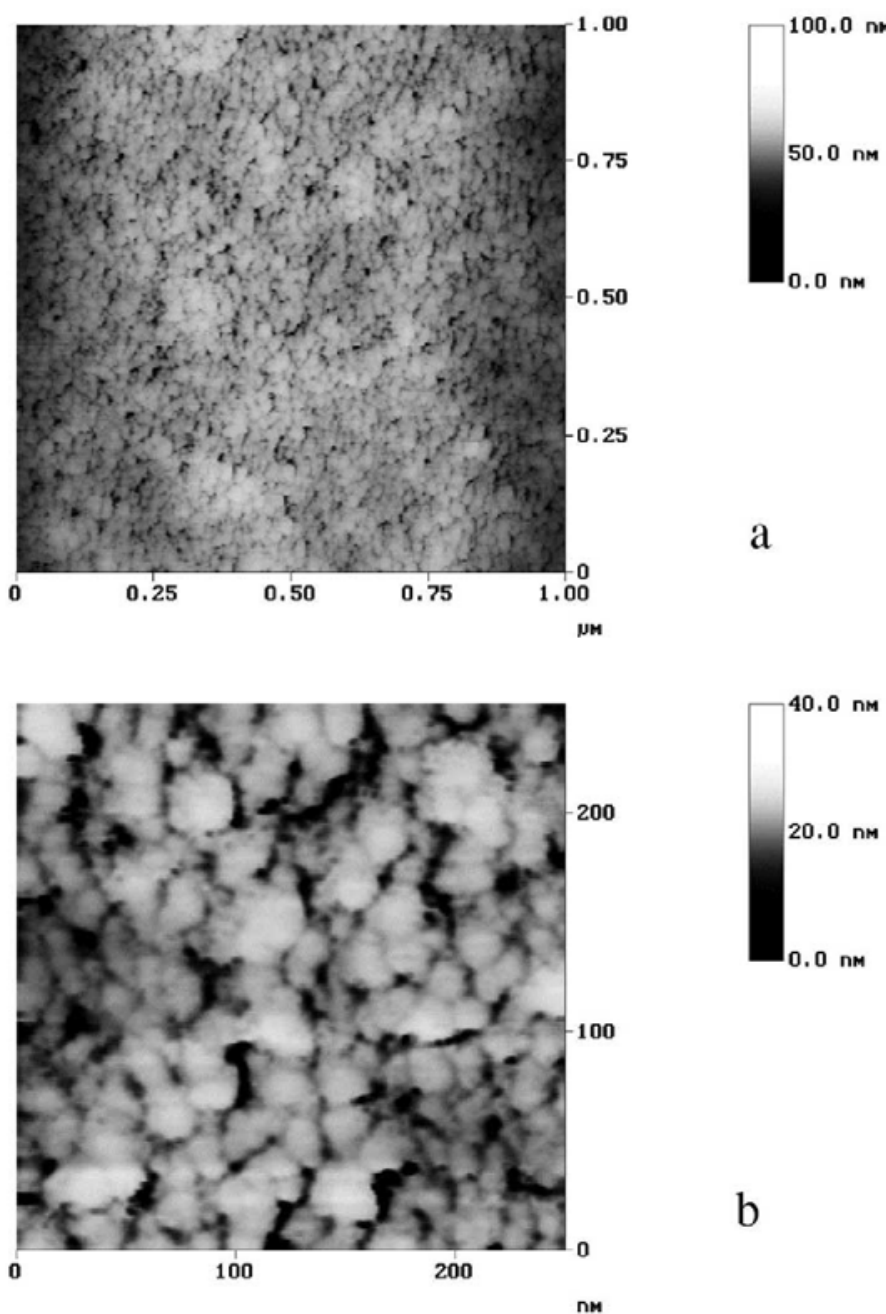

a

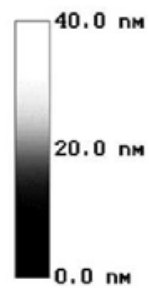

$\mathrm{b}$

Fig. 5. STM images (low (a) and high (b) magnification) of carbon fibre treated by oxygen plasma at $150 \mathrm{~W}$ for 5 min.

laser-induced damage could be observed under the optical microscope.

\subsection{XPS}

The XPS survey spectra of the carbon fibres (Fig. 7) show lines of organic $\mathrm{C}$ and $\mathrm{O}$. The oxygen signal is stronger for the fibres exposed to oxygen plasma. However, at higher power and longer time of exposure $(150 \mathrm{~W} / 5 \mathrm{~min})$, the surface oxidative effect declines significantly.

In Fig. 8, surface atomic O/C ratios determined by XPS are compared with the bulk atomic $\mathrm{O} / \mathrm{C}$ ratios obtained by conventional chemical analysis. For the fresh carbon fibre both ratios are close to each other, the difference between bulk and surface concentrations becoming much more pronounced after exposure to the oxygen plasma. Assuming that carbon is homogeneously distributed in the of the fibre and that the maximal XPS sampling depth is $16 \mathrm{~nm}$, a cursory examination of Fig. 8 shows that in the untreated fibre oxygen is rather homogeneously distributed between bulk and surface as well. On the contrary, in the case of the plasma-treated samples the oxygen concentration presents a sharp difference between surface and bulk, being considerably higher on the former. This is obviously a consequence of diffusion limitations in the plasma oxidation processes and confirms that this treatment introduces stable oxygen functionalities on carbon surfaces. As was noted for Fig. 7 , it is observed in Fig. 8 that the most severe plasma treatment (150 W/5 min) does not bring about necessarily the highest levels of oxygen on the surface. Rather, a saturation level is reached quite early upon treatment.

Fig. 9a-c presents high resolution $\mathrm{C} 1 \mathrm{~s}$ and $\mathrm{O} 1 \mathrm{~s}$ envelopes for the virgin and oxygen plasma-treated fibres. It can be noticed that the total fraction of the C1s envelope 


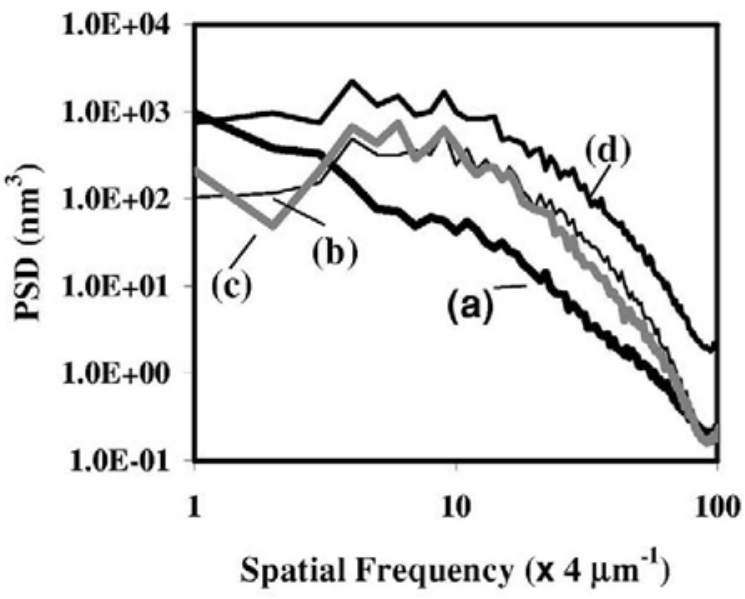

Fig. 6. Plot of the power spectral density (PSD) versus spatial frequency of the fresh and plasma-treated fibres as calculated from their STM images (a, untreated; b, $50 \mathrm{~W}$ for $1 \mathrm{~min}$; c, $75 \mathrm{~W}$ for 3 min; d, $150 \mathrm{~W}$ for $5 \mathrm{~min}$ ).

associated with oxygen environments (shoulders located on the high energy side of the main peak at $284.5 \mathrm{eV}$ ) is greater for the samples processed by oxygen plasma. Unlike the case of, e.g., XPS of oxygen K edge XANES [63], XPS is not capable of resolving the individual contributions of functionalities such as hydroxyl-ester, carbonyl, carboxyl, anhydrides or lactones. However, following previous work in the literature, a semi-quantitative description of the differences was attempted using a curve-fitting procedure [15,64]. Results from this fitting are given in Table 3. The peak at $284.5 \mathrm{eV}$, corresponding to graphitic plus aliphatic $\mathrm{C}$, represents $77 \%$ of the total $\mathrm{C} 1 \mathrm{~s}$ envelope for the fresh fibres versus $64 \%$ for the samples treated at $50 \mathrm{~W} / 1 \mathrm{~min}$ or $150 \mathrm{~W} / 5 \mathrm{~min}$. This indicates that the level of oxygenated functionalities already increases in the initial stages of the plasma treatment, after which some saturation occurs and the $\mathrm{O} / \mathrm{C}$ ratio decreases slightly (see Fig. 8). The width of the graphite peak also increases slightly from about 1 to $1.14 \mathrm{eV}$ following the plasma treatment, suggesting that disordering of the carbon lattice might result from oxidation. These results are similar to those reported previously by other authors in treating carbon fibres [64-66] and polymers [67] with oxygen or oxygen-containing plasmas.

The XPS spectrum of the untreated fibre exhibits oxidized carbon peaks (Fig. 9a, Table 3), the most abundant one being the hydroxyl and/or ether groups, which represents $7 \%$ of the C1s intensity. Upon oxygenplasma treatment, the peaks from oxidized carbon increased in relative intensity. The carboxyl/ester and carbonyl groups reached maxima (each of them amounting to $6 \%$ of the C1s intensity) at $50 \mathrm{~W} / 1$ min and the same at $150 \mathrm{~W} / 5 \mathrm{~min}$, the difference being in the content of hydroxyl/ether groups ( $11 \%$ of the total C1s intensity for the $150 \mathrm{~W} / 5 \mathrm{~min}$ sample versus only $8 \%$ for the sample treated at $50 \mathrm{~W} / 1 \mathrm{~min})$.

The interpretation of the $\mathrm{O} 1 \mathrm{~s}$ spectrum is not so straightforward because the relaxation energies associated with $\mathrm{O} 1 \mathrm{~s}$ core ionization are not a simple function of structure; in addition, $\mathrm{O} 1 \mathrm{~s}$ and $\mathrm{C} 1 \mathrm{~s}$ regions probe different depths into the surface. Nevertheless, we tentatively used peak assignments given by Zielke et al. [68] as follows: $531 \mathrm{eV}, \mathrm{CO}$ groups; $532.2 \mathrm{eV}$, carbonyl oxygen atoms in esters, amides, anhydrides and oxygen atoms in hydroxyls or ethers; $533.2 \mathrm{eV}$, ether oxygen atoms in esters and anhydrides; $534.1 \mathrm{eV}$, oxygen atoms in

Table 1

Pore volumes and surface areas of selected samples investigated

\begin{tabular}{|c|c|c|c|c|}
\hline & $\begin{array}{r}\mathrm{CO}_{2}, 273 \mathrm{~K} \\
V_{\mathrm{DR}}\left(\mathrm{cm}^{3} \mathrm{~g}_{21}\right)\end{array}$ & $\begin{array}{c}\mathrm{N}_{2}, 77 \mathrm{~K} \\
p_{\text {rpo } 50.90}\left(\mathrm{~cm}_{3} \mathrm{~g}^{1}\right)\end{array}$ & $\begin{array}{l}\mathrm{CO}_{2}, 273 \mathrm{~K} \\
S_{\operatorname{mp}}\left(\mathrm{m}^{2} \mathrm{~g}_{21}\right)\end{array}$ & $\begin{array}{c}\mathrm{N}_{2}, 77 \mathrm{~K} \\
S_{\text {в Е т }}\left(\mathrm{m}_{2} \mathrm{~g}_{2}\right)\end{array}$ \\
\hline Untreated & 0.13 & $3.6 \mathrm{E} 204$ & 377 & 0.36 \\
\hline $50 \mathrm{~W} / 1 \mathrm{~min}$ & 0.17 & 1.1Е203 & 467 & 1.4 \\
\hline $75 \mathrm{~W} / 3 \mathrm{~min}$ & 0.15 & - & 412 & - \\
\hline $150 \mathrm{~W} / 5 \mathrm{~min}$ & 0.14 & 2.1E202 & 382 & 23 \\
\hline
\end{tabular}

Table 2

Relative intensities (I), positions $(n)$ and widths (W) of the different bands in the first-order Raman spectra of selected samples

\begin{tabular}{|c|c|c|c|c|c|c|c|c|c|}
\hline & Laser power & $\begin{array}{l}n_{G} \\
\left(\mathrm{~cm}^{21}\right)\end{array}$ & $\begin{array}{l}W_{\mathrm{G}} \\
(\mathrm{cm})\end{array}$ & $\begin{array}{l}n_{\mathrm{D}} \\
\left(\mathrm{cm}_{21}\right)\end{array}$ & $\begin{array}{l}W_{\mathrm{D}} \\
(\mathrm{cm})\end{array}$ & $\begin{array}{l}n_{\triangleright} \\
\left(\mathrm{cm}_{21}\right)\end{array}$ & $\begin{array}{l}W_{\mathrm{D \ominus}} \\
(\mathrm{cm})\end{array}$ & $W_{\mathrm{D}} / W_{\mathrm{G}}$ & $\overline{I_{\mathrm{D}} / I}$ \\
\hline \multirow[t]{2}{*}{ Untreated } & $20 \mathrm{~mW}$ & 1597 & 79.5 & 1350 & 214.9 & 1523 & 98.7 & 2.70 & 3.80 \\
\hline & $100 \mathrm{~mW}$ & 1588 & 80.8 & 1346 & 205.4 & 1505 & 97.6 & 2.54 & 4.19 \\
\hline \multirow[t]{2}{*}{$50 \mathrm{~W} / 1 \mathrm{~min}$} & $20 \mathrm{~mW}$ & 1601 & 76.0 & 1349 & 210.2 & 1528 & 105.7 & 2.77 & 3.88 \\
\hline & $100 \mathrm{~mW}$ & 1589 & 81.1 & 1347 & 209.3 & 1509 & 93.9 & 2.58 & 4.39 \\
\hline \multirow[t]{2}{*}{$150 \mathrm{~W} / 5 \mathrm{~min}$} & $20 \mathrm{~mW}$ & 1599 & 76.3 & 1350 & 216.7 & 1528 & 106.9 & 2.84 & 4.29 \\
\hline & $100 \mathrm{~mW}$ & 1597 & 78.9 & 1349 & 204.3 & 1509 & 78.9 & 2.59 & 4.06 \\
\hline
\end{tabular}




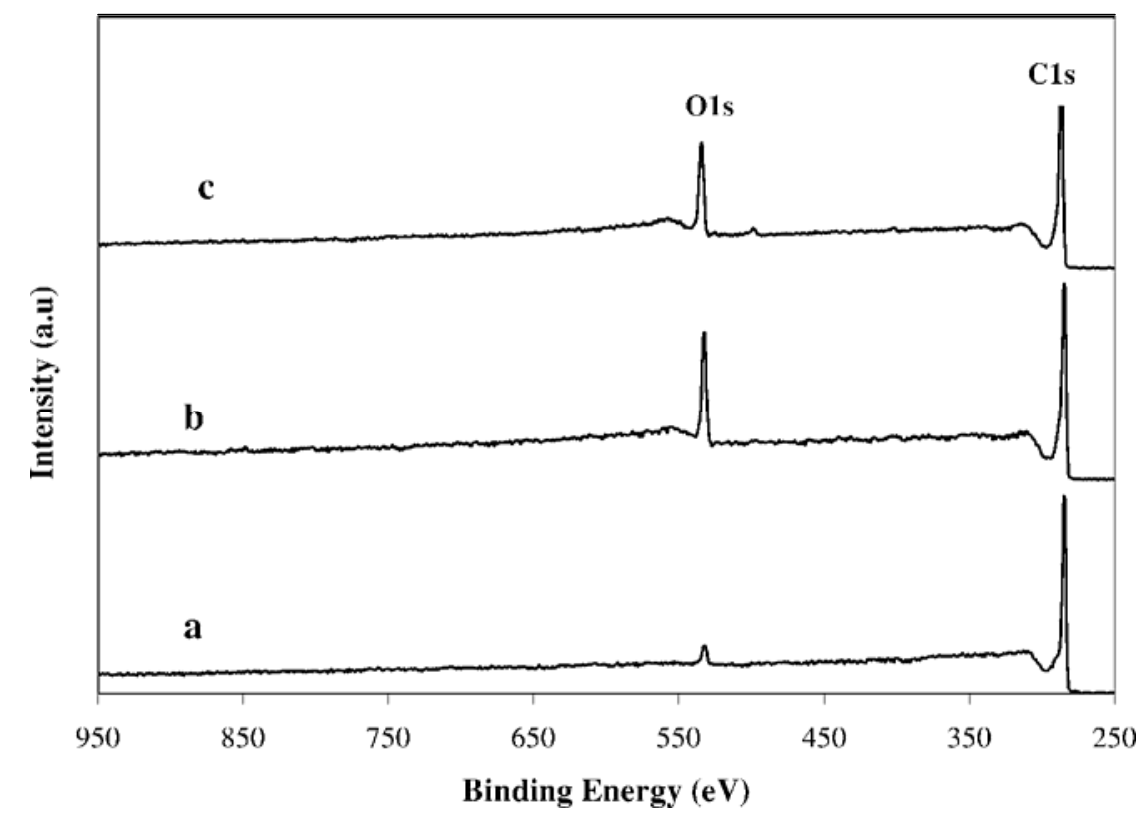

Fig. 7. XPS survey spectra from the fresh and plasma-etched fibres (a, untreated; b, $50 \mathrm{~W}$ for $1 \mathrm{~min}$; c, $150 \mathrm{~W}$ for 5 min).

groups; and $536 \mathrm{eV}$, water. As Fig. 8a-c shows, a shift of the O1s spectrum toward higher binding energy occurs following the treatment at $50 \mathrm{~W} / 1 \mathrm{~min}$, and to a smaller extent at $150 \mathrm{~W} / 5 \mathrm{~min}$. Such a shift is frequently observed when decreasing the XPS electron take-off angle during cross-section examination of oxidized carbon fibres, and can be correlated with the carbonyl band in the C1s core-level spectra [69]. Accordingly, the carboxyl band occurring at ca. $534 \mathrm{eV}$ [68] becomes relatively stronger upon plasma oxidation, as shown in Table 4, reaching after the treatments at $50 \mathrm{~W} / 1 \mathrm{~min}$ and $150 \mathrm{~W} / 5 \mathrm{~min}$ as much as $11 \%$ and $12 \%$, respectively, of the total O1s intensity in comparison with only $3 \%$ for the parent carbon fibre. This

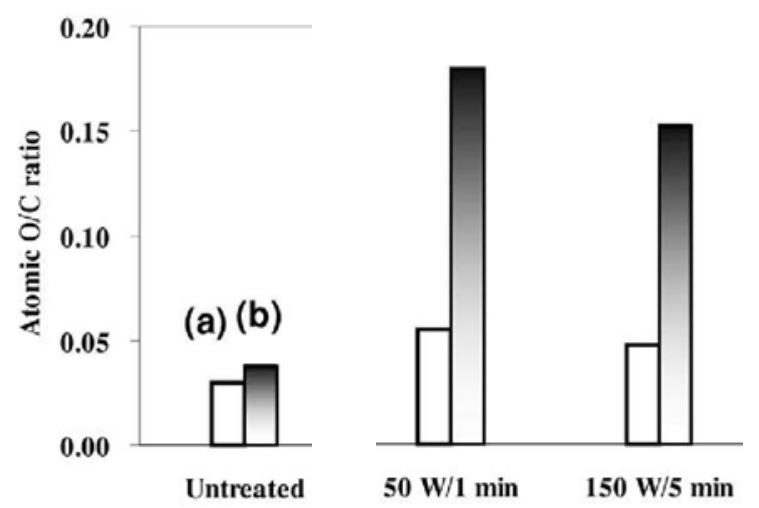

Fig. 8. Comparison of atomic $\mathrm{O} / \mathrm{C}$ ratios obtained by bulk chemical analysis (a) and XPS (b) of carbon fibres untreated and treated by oxygen plasma. is somewhat in accordance with the above-discussed sequence for the intensity of the $288.4 \mathrm{eV}$ peak (carboxyl/ or ester groups) in the C1s spectrum.

\section{6. $T P D$}

The total integrated amounts of $\mathrm{CO}_{2}$ and $\mathrm{CO}$ above 450 $\mathrm{K}$, released by TPD (Fig. 10), follow a similar trend to that for the micropore volume determined by $\mathrm{CO}_{2}$ adsorption (Table 1). TPD profiles $\left(20 \mathrm{~K} \mathrm{~min}^{2}\right.$ ) below $1700 \mathrm{~K}$ are presented in Fig. 11a-e. In TPD experiments, carboxylic acids/esters/lactols and lactones/anhydrides/peroxides are generally assumed to evolve as $\mathrm{CO}_{2}$, and anhydrides/ phenols and hydroquinones/carbonyls, quinones and ethers to evolve as $\mathrm{CO}$, in an approximately increasing order of temperatures [17].

Keeping in mind that thermally evolved $\mathrm{CO}_{2}$ can derive from a broad range of structural moieties, the $\mathrm{CO}_{2}$ peak at 550-650 K can be tentatively assigned to carboxyl groups. $\mathrm{A} \mathrm{CO}_{2}$ pseudo-plateau ranging from about $600 \mathrm{~K}$ to about $950 \mathrm{~K}$ could result from the decomposition of lactones. Some $\mathrm{CO}_{2}$ complexes in the studied samples could arise either from ambient exposure after carbonisation (for the initial fibre) or enhanced ambient oxidation, as a result of surface cleaning (degassing1etching) and/or an increase in surface energy (for the plasma-treated fibres).

As Fig. 1 1a shows, $\mathrm{CO}_{2}$ evolution from the parent fibres is characterized, after a first peak at low temperatures corresponding to the desorption of physisorbed $\mathrm{CO}$, by a pseudo-plateau above about $575 \mathrm{~K}$ covering more or less the whole range from carboxylic acids to lactones. A 

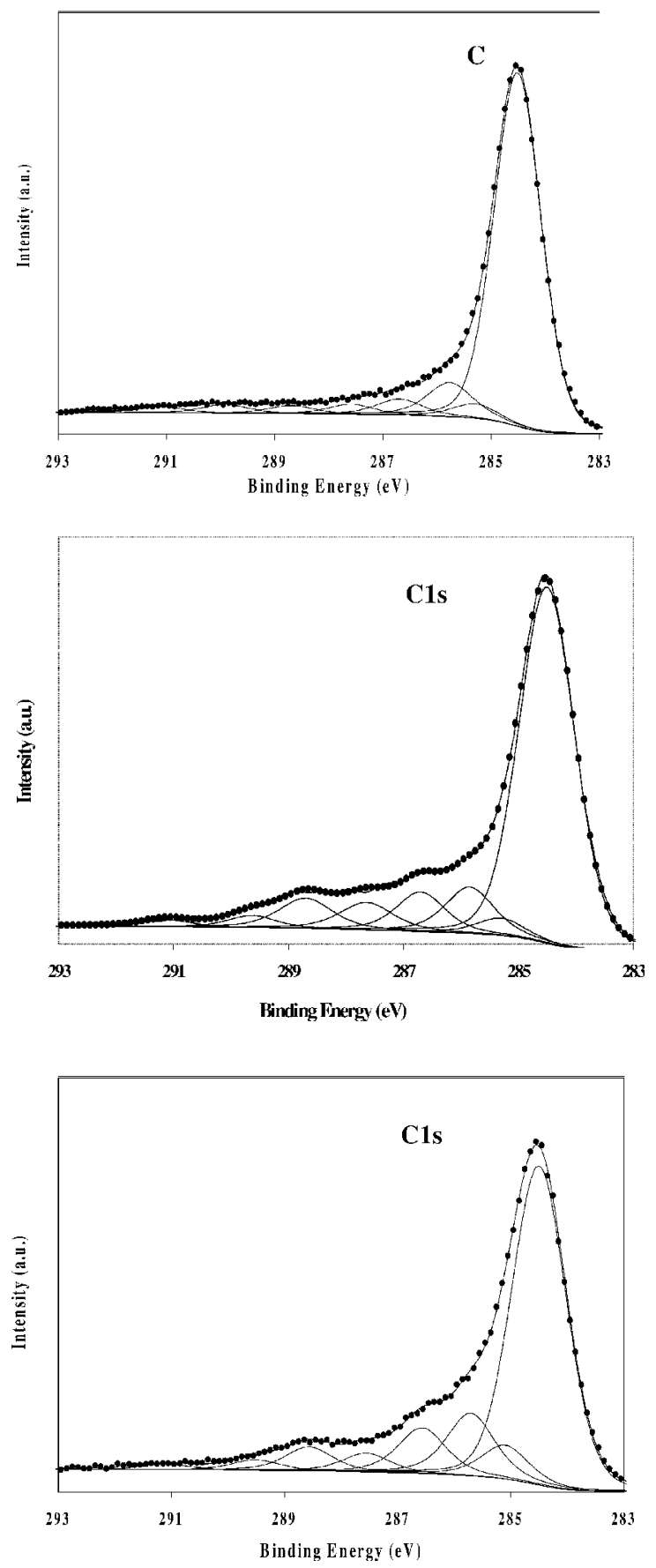
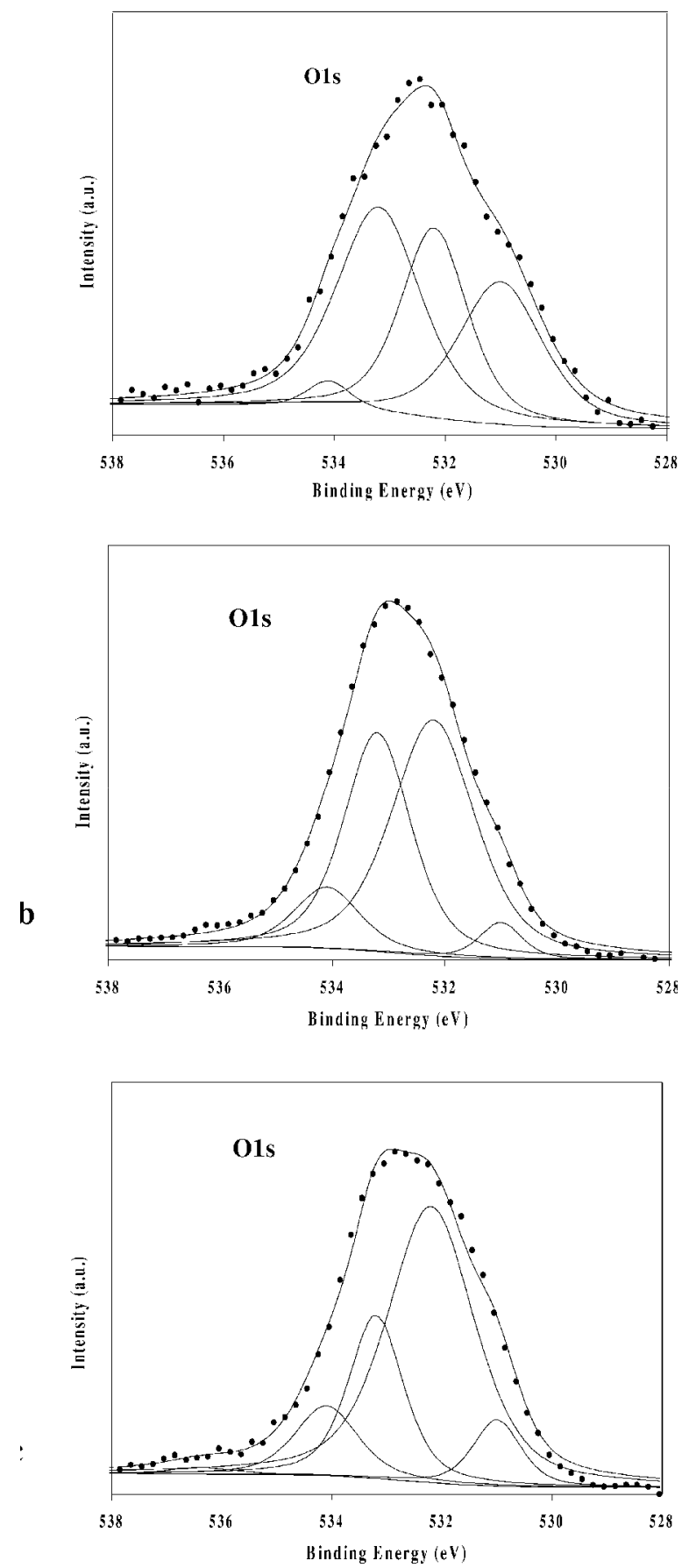

Fig. 9. C1s and O1s XPS spectra of carbon fibres untreated and plasma-treated: (a) untreated; (b) 50 W/1 min; (c) 150 W/5 min.

similarly broad continuum from 400 to $800 \mathrm{~K}$ has been reported by Marchon et al. [70] after $\mathrm{H}_{2} \mathrm{O}$ adsorption on graphite, as opposed to well-defined peaks reported after $\mathrm{O}_{2} / \mathrm{CO} / \mathrm{CO}_{2}$ adsorption on the same substrate. The $\mathrm{CO}_{2}$ evolution upon TPD can be due to decomposition of $\mathrm{CO}_{2}$ complexes and/or other oxygen surface complexes read- sorption and/or surface reactions phenomena that take place by possible secondary reactions. $\mathrm{CO}_{2}$ complexes in the parent fibre probably arise from ambient exposure and also as well as surface reconstruction during sample cooling and storage, since carbonisation of the fibres should have eliminated most if not all such functionality 
Table 3

Relative area (\%) of C1s XPS of carbon fibres treated by oxygen plasma (peak 1, C-C; peak 2, b-carbon of HBS; peak 3, -C-OH, C-O-C-; peak 4, hydrogen-bridged oxide structure (HBS); peak 5, C=O; peak 6, COOH, COOR; peaks 7 and 8, COs ${ }^{2}$, p-p*)

\begin{tabular}{|c|c|c|c|c|c|c|c|}
\hline & Peak 1 & & & & & & \\
\hline & $284.5 \mathrm{eV}$ & $285.2 \mathrm{eV}$ & $285.9 \mathrm{eV}$ & $286.7 \mathrm{eV}$ & $287.6 \mathrm{eV}$ & $288.5 \mathrm{eV}$ & $289.6-291.1 \mathrm{eV}$ \\
\hline Untreated & 76 & 3 & 7 & 3 & 2 & 2 & 7 \\
\hline $50 \mathrm{~W} / 1 \mathrm{~min}$ & 64 & 4 & 8 & 7 & 5 & 6 & 6 \\
\hline $150 \mathrm{~W} / 5 \mathrm{~min}$ & 63 & 4 & 11 & 8 & 4 & 5 & 6 \\
\hline
\end{tabular}

Table 4

Relative area (\%) of O1s XPS of carbon fibres treated by oxygen plasma (peak 1, CO; peak 2, carbonyl in ester, amide, anhydride and oxygen in hydroxyl and ether; peak 3, ether oxygen in ester and anhydride; peak 4, COOH; peak 5, water)

\begin{tabular}{lcccc}
\hline & Peak 1 & Peak 2 & Peak 3 & $\begin{array}{c}\text { Peak 4 } \\
534.1 \mathrm{eV}\end{array}$ \\
\hline Untreated & $531.0 \mathrm{eV}$ & $532.2 \mathrm{eV}$ & $533.2 \mathrm{eV}$ & 3 \\
$50 \mathrm{~W} / 1 \mathrm{~min}$ & 26 & 32 & 38 & 0 \\
$150 \mathrm{~W} / 5$ min & 7 & 43 & 40 & 0 \\
\hline
\end{tabular}

which might have been introduced previously during the oxidative stabilization treatment (CO complexes are a different case, since they desorb at higher temperatures and might have been preserved upon carbonisation). PradoBurguete et al. [71] reported that a carbon black defunctionalised by heating in $\mathrm{H}_{2}$ evolved the same amount of $\mathrm{CO}_{2}$ as the parent carbon black, and attributed this finding to a regeneration of the $\mathrm{CO}_{2}$ complex by room temperature oxidation during storage. As concerns the $\mathrm{H}_{2} \mathrm{O}$ evolved, the low temperature peak associated with $\mathrm{H}_{2} \mathrm{O}$ physisorption is followed by a gradual intensity decrease with prominent features at about $550 \mathrm{~K}$ and about $1200 \mathrm{~K}$. Water H-bonded to carboxylic acids would justify the $550 \mathrm{~K}$ feature, with an alternative or concurrent mechanism being partial condensation of carboxylic acids into anhydrides which would then evolve as both $\mathrm{CO}$ and $\mathrm{CO}_{2}$ at higher temperatures. The second feature at about
$1200 \mathrm{~K}$ can hardly be related with condensation since the only oxygenated species likely to be remaining at this temperature are quinones, and the temperature is too high to prevent any $\mathrm{H}$-bonded $\mathrm{H}_{2} \mathrm{O}$ from desorbing. Judging from concurrent species evolution as seen in Fig. 11 a, this water could result from a secondary reaction between $\mathrm{H}_{2}$ and $\mathrm{CO}_{2}$, which is more energetically favourable at this temperature.

Upon oxygen plasma treatment (Fig. 11b-e), peaks at about 550-650 K grow in both $\mathrm{CO}_{2}$ and $\mathrm{H}_{2} \mathrm{O}$ profiles, with their intensity first increasing with increasing severity of treatments at $20 \mathrm{~W} / 1 \mathrm{~min}$ and $50 \mathrm{~W} / 1 \mathrm{~min}$, and later reaching a saturation level or slightly receding at $75 \mathrm{~W} / 3$ min, to finally decrease for the most severe treatment of $150 \mathrm{~W} / 5 \mathrm{~min} . \mathrm{H}_{2} \mathrm{O}$ evolution from this last fibre is the same as for the parent, untreated sample, while in the $\mathrm{CO}_{2}$ profile the intensity at $550 \mathrm{~K}$ for this fibre is even lower

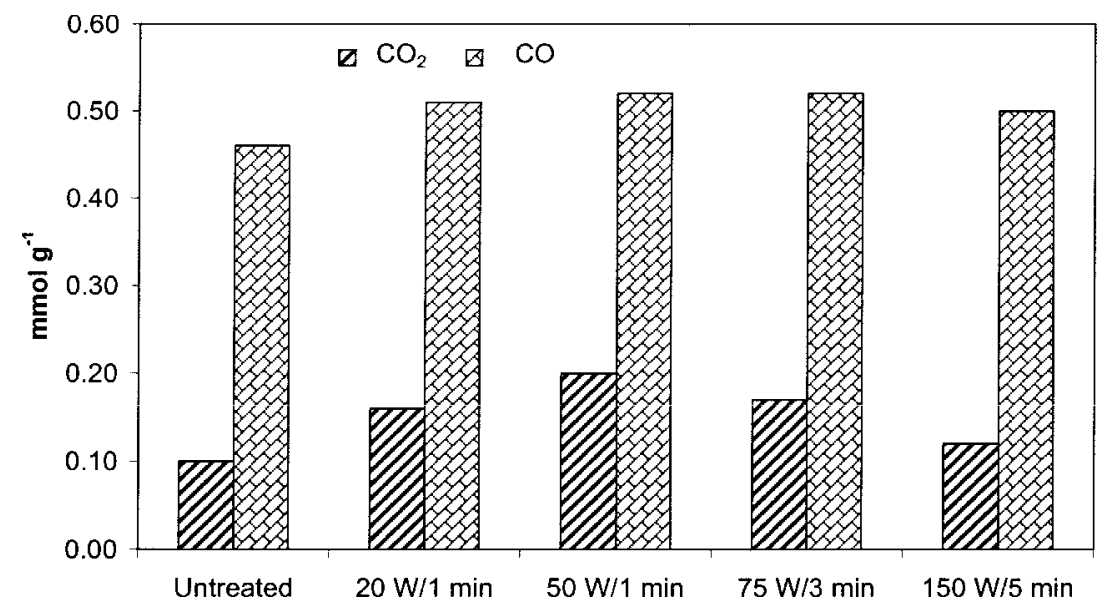

Fig. 10. TPD yields of $\mathrm{CO}$ and $\mathrm{CO}_{2}$ of carbon fibres untreated and plasma-treated. 

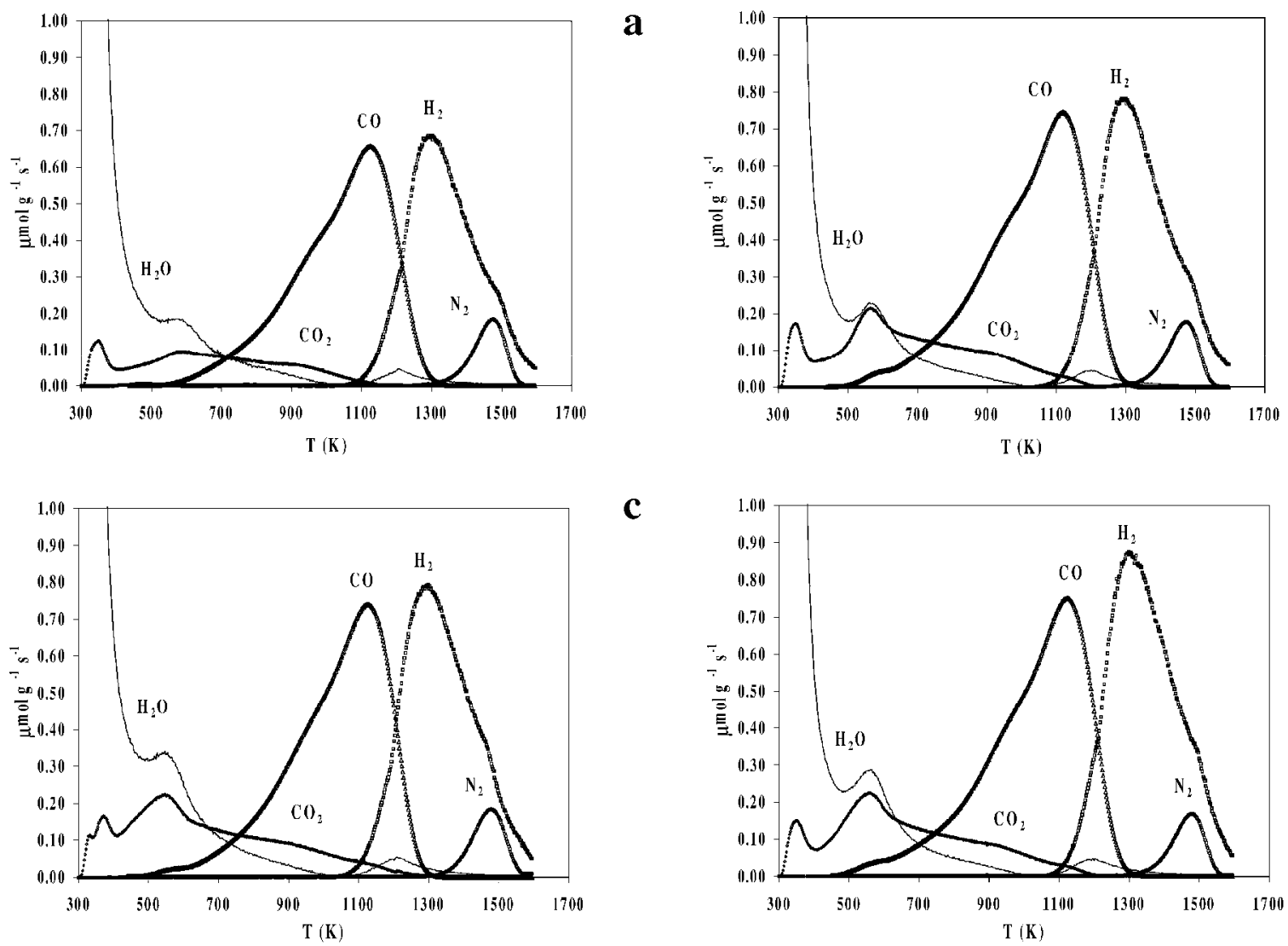

C

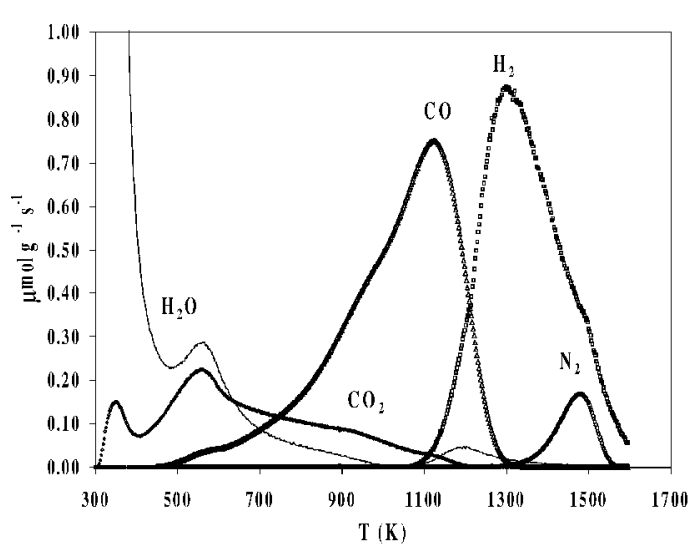

d

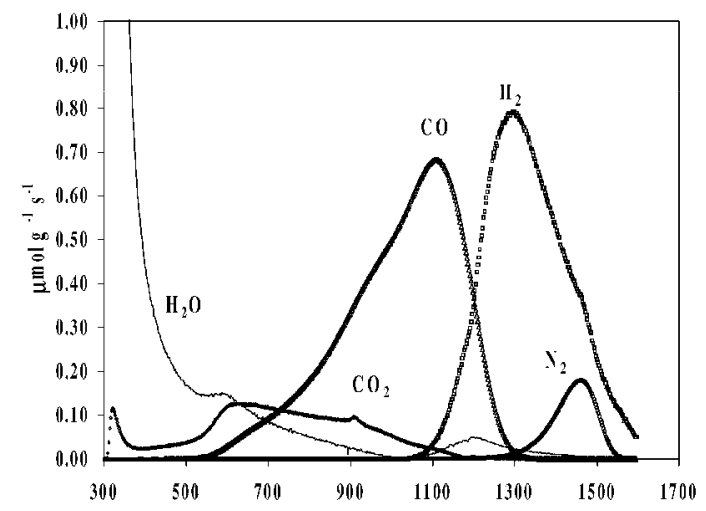

$\mathbf{e}$

Fig. 11. TPD profiles of untreated and plasma-treated carbon fibres: (a) untreated sample, (b) $20 \mathrm{~W}$ for $1 \mathrm{~min}$, (c) $50 \mathrm{~W}$ for $1 \mathrm{~min}$, (d) $75 \mathrm{~W}$ for 3 min, (e) $150 \mathrm{~W}$ for $5 \mathrm{~min}$.

than that of the original fibre, with the effect that the pseudo-plateau starts at a slightly higher temperature. Both peaks are fairly safely assigned to carboxylic acid groups with $\mathrm{H}$-bonded $\mathrm{H}_{2} \mathrm{O}$. Comparison of TPD results with those obtained by XPS shows that abundant carboxylic groups, which can contribute the most to the surface acidity [72,73], are introduced into the exterior surface of the carbon fibre, particularly for the plasma treatment at 50 W/ 1 min. An enhanced relative presence of acidic carboxyl groups is consistent with the $\mathrm{C} 1 \mathrm{~s}$ features near $288.4 \mathrm{eV}$ (carboxyl and/or ester groups), and also with the $\mathrm{O} 1 \mathrm{~s}$ feature near $534 \mathrm{eV}$ (assigned to carboxylic arids) 
$\mathrm{H}_{2}$ evolution started at $1100 \mathrm{~K}$ (temperature which agrees well with the expected fibre carbonisation temperature) for all samples, with a major maximum at about 1350 $\mathrm{K}$. The effect of hydrogen on the thermal desorption of $\mathrm{C}(\mathrm{O})$ complexes [74,75], which may explain the small water evolution at ca. $1230 \mathrm{~K}$, is small because the residence time of gases in the microreactor is very low. For the same reason, Boudouard reaction is assumed to be negligible. In the untreated and plasma-treated samples, the CO profile exhibited a very wide peak with a maximum at about $1150 \mathrm{~K}$. This position points towards the predominance of carbonyl/semiquinones, although the peak is broad enough to accommodate other kinds of less stable functionalities, such as phenols or anhydrides [76]. Also, a nitrogen peak appears between 1320 and $1564 \mathrm{~K}$ with a maximum at $1480 \mathrm{~K}$. This peak is highly Gaussian and is not affected by the plasma treatments.

The $\mathrm{CO}_{2}$ profile suggests that only carboxyl-type groups (including lactones and esters) were created in an appreciable amount following exposure to the oxygen plasma, with no observable change in the shape of the CO profile, there being only an increase in intensity. This trend is different from the chemical effects reported following surface treatment of carbons with other oxidative agents such as $\mathrm{HNO}_{3}[77,78], \mathrm{H}_{2} \mathrm{O}_{2}[71,79]$, or air [80], whereby $\mathrm{CO}$ and $\mathrm{CO}_{2}$ profiles changed appreciably in terms of both intensity and shape. The apparent increase in the intensity of the $\mathrm{CO}_{2}$ signal at intermediate (TPD) oxygen plasma treatment levels could just come from enhanced ambient oxidation, as a result of surface cleaning and/or surface energy increase upon plasma treatment of the fibres. Both effects have been recognised and reported before [16,29,81].

Changes have also been detected affecting the thermal desorption of physisorbed $\mathrm{CO}_{2}$ onto the fibres, with physisorption increasing upon plasma treatment (Fig. 11) for the less severe treatments. Again, a proviso must be made for the strongest treatment, for which $\mathrm{CO}_{2}$ physisorption is actually of lower magnitude than for the parent fibre and takes place at a slightly lower temperature. In this respect, the fibre treated at $50 \mathrm{~W} / 1$ min presents the particularity of having the $\mathrm{CO}_{2}$ physisorption peak split into two, with the lower temperature one being coincident with that of the $150 \mathrm{~W} / 5$ min-treated fibre.

\section{Conclusions}

The present results demonstrate that, from a structural point of view, the changes induced by the plasma treatments on the isotropic carbon fibre surface are rather modest. On the micron scale (SEM investigations), no significant changes were detected in the morphology of the plasma-oxidized samples. Only a high resolution raphical transformations upon plasma-induced etching, which involved a general increase in nanometre scale surface roughness. In this respect, the relatively small rise observed in the BET surface areas following the plasma treatments can be mainly ascribed to the aforementioned topographical evolution and not to a reduction in fibre diameter, which the SEM measurements did not support.

Microstructurally, the as-received fibre is already a highly disorganized carbon material, as the Raman spectra revealed. However, the initial disorder is enhanced a bit upon oxidation in the plasma. This can be understood by the fact that the introduction of oxygen functionalities evidenced by XPS and TPD is at least partly made at the expense of the removal of carbon atoms from the fibre surface due to their reaction with the active species from the plasma (oxygen atoms). Since oxygen atoms are known to attack both perfect and defect sites of carbon structures $[27,28]$, one would expect that the proportion of the former, already limited in the starting material, should be further reduced on the surface with the treatments. As a matter of fact, this is the trend outlined in the Raman measurements.

Although STM imaging failed to reveal atomically resolved structures (a reflection of the highly disorganized carbon structure of this material) and therefore direct visual evidence could not be gathered, we expect that, based on previous work on graphite [28], plasma etching will proceed by initially creating tiny voids which may subsequently widen with increased treatment severity. This would explain the initial increase followed by a decrease in $V_{\mathrm{DR}}$ micropore volume observed in the fibres with plasma treatment (Table 1)

Concerning the surface chemistry, the results presented in this work show that stable oxygen functionalities are introduced on the fibre surface by means of oxygen plasma. Both XPS and TPD measurements indicated an early saturation of oxygen on the fibres upon plasma treatment, i.e. the oxygen concentration reached its maximum after a short exposure (50 W/1 min) and longer, more intense treatments $(150 \mathrm{~W} / 5 \mathrm{~min})$ were not able to provide higher levels of surface oxidation. The ultimate reason for this behaviour is extremely difficult to ascertain due to the complexity of the factors that might be playing a role. However, a tentative and partial explanation could be provided by noting that the small decline in total oxygen concentration of the $150 \mathrm{~W} / 5 \mathrm{~min}$ sample (compared to the $50 \mathrm{~W} / 1 \mathrm{~min}$ one) is concur ${ }^{\mathrm{r}}$ ent with a reduction in micropore volume, $V_{\mathrm{DR}}$. This parameter reflects the amount of small micropores $(, 0.7 \mathrm{~nm})$ present on the fibres. It is reasonable to assume that the entrances of these tiny pores are places where oxygen may easily chemisorb [82], so a reduction in the number of micropores present on the fibre surface should affect the surface oxygen concentration accordingly. As a consequence, gentle plasma treatments could suffice to provide a large increase in the amount of external surface oxygen functionalities, carboxyl-type 
groups in particular. More intense treatments would in this regard prove to be somewhat detrimental.

\section{A cknowledgements}

Support from scientific exchange grants from CNRS (France) and CSIC (Spain) and financial support from the Spanish DGICYT (project PB98-0492) is gratefully acknowledged. Raman and XPS were performed in collaboration with ITODYS, Univ. Paris 7, France and the School of Mechanical and Materials Engineering at the University of Surrey, UK.

\section{$R$ eferences}

[1] Berchmans S, Vijayavalli R. Langmuir 1995;11:286-90.

[2] Steffen HJ, Schmidt J, Gonzalez-Elipe' AR. Surf Interface Anal 2000;29(6):386-91.

[3] Chu X, Kinoshita K. Mater Sci Eng B Solid State Mater Adv Technol 1997;49(1):53-60.

[4] Blyth RIR, Buqa H, Netzer FP, Ramsey MG, Besenhard JO, Golob P et al. Appl Surf Sci 2000;167(1-2):99-106.

[5] Walter KC, Kung HH, Maggiore CJ. Appl Phys Lett 1997;71(10):1320-2.

[6] Muhl T, Kretz J, Monch I, Schneider CM, Bruckl H, Reiss G. Appl Phys Lett 2000;76(6):786-8.

[7] Hamerton I, Hay JN, Howlin BJ, Jones JR, Lu SY, Webb GA et al. Chem Mater 1997;9(9):1972-7.

[8] Oyama HT, Wightman JP. Surf Interface Anal 1998;26(1):39-55.

[9] Feih S, Schwartz P. J Adhes Sci Technol 1998;12:523-39.

[10] Pittman CU, Jiang W, Yue ZR, Gardner S, Wang L, Toghiani H et al. Carbon 1999;37:1797-807.

[11] Yue ZR, Jiang W, Wang L, Gardner SD, Pittman Jr. CU. Carbon 1999;37:1785-96.

[12] Bismarck A, Kumru ME, Springer J. J Colloid Interface Sci 1999;210:60-72.

[13]Bismarck A, Righter D, Wuertz C, Kumru ME, Song B, Springer J. J Adhes 2000;73(1):19-42.

[14] Moon SI, Jang J. J Adhes Sci Technol 2000;14(4):493-506.

[15] Viswanathan H, Wang YQ, Audi AA, Allen PJ, Sherwood PMA. Chem Mater 2001;13(5):1647-55.

[16] Montes-Moran' MA, Martınez-Alonso' A, Tascon' JMD Young RJ. Comp A Appl Sci Manuf 2001;32(3-4, SI):36171.

[17]Boehm HP. Carbon 1994;32:759-66.

[18]Leon y Leon CA, Radovic LR. Interfacial chemistry and electrochemistry of carbon surfaces. In: Thrower PA, editor, Chemistry and physics of carbon, vol. 24, New York: Marcel Dekker, 1992, pp. 213-310.

[19] Lopez-Ramann MV, Stoeckli F, Moreno-Castilla C, CarrascoMarin F. Carbon 1999;37(8):1215-21.

[20] Donnet JP, Bansal RC. In: 2nd ed, Carbon fibres, New York: Marcel Dekker, 1990.

[21]Fitzer E, Weiss R. Carbon 1987;25(4):455-67.

[22]Paiva MC, Bernardo CA, Nardin M. Carbon 2000;38(9):1323-37.
[24]Dilsiz N. J Adhes Sci Technol 2000;14(7):975-87.

[25] Perakslis ED, Gardner SD, Pittman CU. J Adhes Sci Technol 1997;11(4):531-51.

[26] Evans JF, Kuwana T. Anal Chem 1979;51(3):358-65.

[27] Takada T, Nakahara M, Kumagai H, Sanada Y. Carbon 1996;34(9):1087-91.

[28] Paredes JI, Martınez-Alonso'A, Tascon’ JMD. J Mater Chem 20

[29] Paredes JI, Martinez-Alonso A, Tascon' JMD. Carbon 2000;38(8):1183-97.

[30] Jones C, Sammann E. Carbon 1990;28(4):509-14.

[31] Ohte T, Kojima A, Katoh M, Kamata K, Ohtani S. Carbon 1994;32(1):177-81.

[32] Maas AJH, Viitanen MM, Brongersma HH. Surf Interface Anal 2000;30(1):3-6.

[33] Carlotti S, Mas A. J Appl Polym Sci 1998;69(12):2321-30.

[34]Poncin-Epaillard F, Brosse JC, Falher T. Macromol Chem Phys 1999;200(5):989-96.

[35] Dupont-Gillain CC, Adriaensen Y, Derclaye S, Rouxhet PG. Langmuir 2000;16(21):8194-200.

[36] Garcia AB, Cuesta A, Montes-Moran MA, Martinez-Alonso A, Tascon’ JMD. J Colloid Interface Sci 1997;192(2):363-7.

[37] Cuesta A, Martınez-Alonso'A, Tascon' JMD. Bol Soc Chil 'Quı

[38] Garcia AB, Martinez-Alonso A, Leon y Leon CA, Tasc6n JMD. Fuel 1998;77(6):613-24.

[39]Cuesta A, Dhamelincourt P, Laureyns J, Martınez-Alonso' A, Tas

[40] Cascarini de Torre LE, Bottani EJ, Martınez-Alonso' A Cuesta A, Garcia' $\quad$ AB, Tascon' $\quad$ JMD. Carbon 1998;36(3):277-82

[41] Boudou JP, Martınez-Alonso'A, Tascon JMD. Carbon 2000;38

[42] Cuesta A, Martnez-Alonso' A, Tascon' JMD. Carbon 2001;39(8

[43]Fang SJ, Haplepete S, Chen W, Helms CR, Edwards H. J Appl Phys 1997;82(12):5891-8.

[44]Gregg SJ, Sing KSW. In: 2nd ed, Adsorption, surface area and porosity, London: Academic Press, 1982.

[45]Briggs D, Seah MP. In: Auger and X-ray photoelectron spectroscopy, 2nd ed, Practical surface analysis, vol. 1, Chichester: John Wiley, 1990.

[46]Ton-That C, Shard AG, Bradley RH. Langmuir 2000;16(5):2281-4.

[47]Wagner CD, Davis LE, Zeller MV, Taylor JA, Raymond RH, Gala LH. Surf Interface Anal 1981;3:211-8.

[48] Turner JA, Thomas KM. Langmuir 1999;15(19):6416-22.

[49] Stanczyk K, Boudou JP. Fuel 1994;73(6):940-4.

[50] Brault P, Dumas P, Salvan F. J Phys Condens Matter 1998;10(1):L27-32.

[51] Garrido J, Linares-Solano A, Martin-Martinez JM, MolinaSabio M, Rodriguez-Reinoso' F, Torregrosa R. Langmuir 1987;3(1):76-81.

[52] Inagaki M, Sunahara M, Shindo A, Vignal V, Konno H. J Mater Res 1999;14(8):3208-10.

[53] Domingo-Garcla’ M, Lopez-Garzon’ FJ, Perez-Mendoza’ M. Car [54] Jang J, Yang H. J Mater Sci 2000;35(9):2297-303.

[55] Lespade PA, Marchand A, Couzi M, Cruege F. Carbon 1984;22(4/5):375-85.

[56] Beny-Bassez C, Rouzaud JN. Scanning Electron Microsc 1985;1:119-24. 
[56] Cuesta A, Dhamelincourt P, Laureyns J, Martınez-Alonso'A, Tas [57] Jawhari T, Roid A, Casado J. Carbon 1995;33(11):1561-5.

[58] Haghseresht F, Lu GQ, Whittaker AK. Carbon 1999;37(9):1491-7.

[59] Nakahara M, Sanada Y. J Mater Sci 1993;28(5):1327-33.

[60] Fukunaga A, Komami T, Ueda S, Nagumo M. Carbon 1999;37(7):1087-91.

[61]Bowden M, Gardiner DJ, Southall JM. Carbon 1993;31(7):1057-60.

[62] Cuesta A, Dhamelincourt P, Laureyns J, Martınez-Alonso'A, Tas

[63] Turner JA, Thomas KM, Russell AE. Carbon 1997;35(7):983-92.

[64] Wang YQ, Zhang FQ, Sherwood PMA. Chem Mater 1999;11(9):2573-83.

[65] Farrow GJ, Atkinson KE, Fluck N, Jones C. Surf Interface Anal 1995;23(5):313-8.

[66] Oyama HT, Wightman JP. Surf Interface Anal 1998;26(1):39-55.

[67] Okell S, Henshaw T, Farrow G, Aindow M, Jones C. Surf Interface Anal 1995;23(5):319-27.

[68] Zielke U, Huttinger" K, Hoffman WP. Carbon 1996;34:983-98.

[69] Gardner SD, He G, Pittman Jr. CU. Carbon 1996;34:1221-8.
[71] Marchon B, Carrazza J, Heinemann H, Somorjai GA. Carbon 1988;26:507-14.

[72] Prado-Burguete C, Linares-Solano A, Rodriguez-Reinoso' F, Salinas-Martınez' de Lecea C. J Catal 1989;115(1):98-106.

[73] Boehm HP, Voll M. Carbon 1970;8(8):227-40.

[74] Otake Y, Jenkins RG. Carbon 1993;31(1):109-21.

[75] Calo JM, Cazorla-Amor6s D, Linares-Solano A, Roman-Martinez MC, Salinas-Martinez de Lecea C. Carbon 1997;35(4):543-54.

[76] Lu W, Calo JM. ACS Fuel Chem Div Prepr 2001;46(2):524-

[77] Fritz OW, Huttinger" KJ. Carbon 1993;31(6):923-30.

[78] Rodriguez-Reinoso’F, Molina-Sabio M. Adv Colloid Interface S [79] de la Puente G, Pis JJ, Menendez'JA, Grange P. J Anal Appl Pyr

[80] Martin-Gullen A, Prado-Burguete C, Rodriguez-Reinoso F. Carbon 1993;31(7):1099-105.

[81] Linares-Solano A, Salinas-Martınez' de Lecea C, CazorlaAmor6s D, Joly JP, Charcosset H. Energy Fuels 1990;4(5):467-74.

[82] Pittman Jr. CU, Jiang W, He G-R, Gardner SD. Carbon 1998;36(1-2):25-37.

[83] Paredes JI, Martinez-Alonso A, Tasc6n JMD. Langmuir 2001;17(2):474-80. 